\title{
PERFIL DOS SISTEMAS DE PRODUÇÃO DE LEITE BOVINO NO SERIDÓ POTIGUAR
}

\author{
J. G. B. GALVÃO JÚNIOR ${ }^{{ }^{*}}$, A. H. N. RANGEL ${ }^{2}$, M. M. GUILHERMINO ${ }^{2}$, L. P. NOVAES ${ }^{2}$ e H. R. MEDEIROS ${ }^{2}$ \\ ${ }^{1}$ Instituto Federal do Rio Grande do Norte \\ ${ }^{2}$ Universidade Federal do Rio Grande do Norte \\ geraldo.junior@ifrn.edu.br
}

Artigo submetido em janeiro/2014 e aceito em abril/2015

DOI: $10.15628 /$ holos.2015.1913

\section{RESUMO}

Objetivou-se neste estudo caracterizar os sistemas de produção de leite bovino instalados na região Semiárida Potiguar, baseado nos aspectos sociais, econômicos e zootécnicos, visando contribuir na manutenção e aprimoramento da atividade leiteira na região. Foram selecionados, aleatoriamente, 28 estabelecimentos agropecuários que desempenhavam a atividade da bovinocultura leiteira com posterior aplicação de questionário estruturado, durante os meses de setembro e outubro de 2011 e os dados analisados com aplicação de medidas de análise descritiva. Os resultados demonstraram que 53,57\% dos entrevistados eram proprietários da terra, a mediana da área das propriedades correspondeu a 135 hectares, a mediana do número de animais no rebanho bovino foi de 51 cabeças, com número mínimo de 11 e máximo de 350 cabeças nos estabelecimentos da amostra, 85,72\% dos estabelecimentos tinham até 23 vacas em lactação, todos aplicavam a técnica de ordenha manual com bezerro ao pé, com produtividade média de 3,91 litros de leite/vaca/dia, $92,86 \%$ dos entrevistados não produziam silagem e/ou feno, 64,29\% não tinham acesso à assistência técnica, a idade média dos entrevistados foi $51 \pm 10,85$ anos de idade, $78,57 \%$ tinham apenas ensino fundamental incompleto, 96,43\%, $100 \%$ e $85,71 \%$ dos estabelecimentos tinha água encanada, energia elétrica e cisternas instalados, respectivamente. Conclui-se que é necessária à inclusão de melhores práticas de manejo do rebanho, escrituração zootécnica, assistência técnica e reorganização fundiária.

PALAVRAS-CHAVE: bovinocultura, Caatinga, escrituração, Nordeste, rebanho.

\section{PROFILE OF PRODUCTION SYSTEMS IN BOVINE MILK SERIDÓ POTIGUAR}

\begin{abstract}
The objective of this study to characterize the bovine milk production systems installed in the Semi-arid region Brazil, based on social, economic aspects and zootechnical, aiming to contribute to the maintenance and improvement of the dairy activity in the region. Were selected randomly, 28 agricultural establishments that played the dairy activity with subsequent application of structured questionnaire, during the months of September and October 2011 and the data analyzed with descriptive analysis measures. The results showed that $53.57 \%$ of respondents were owners of the land, the median of the properties area corresponded to 135 hectares, the median of the number of animals in the beef herd was 51 heads, with minimum number of
\end{abstract}

11 and a maximum of 350 heads in establishments in the sample, $85.72 \%$ of establishments had until 23 lactating cows, all applied the technique of hand milking with calf at foot, with productivity averaging 3.91 liters of milk/cow/day, $92.86 \%$ of respondents did not produced silage and/or hay, $64.29 \%$ had no access to technical assistance, the average age of respondents was $51 \pm 10.85$ years old, $78.57 \%$ had only primary education incomplete, $96.43 \%, 100 \%$ and $85.71 \%$ of establishments had indoor plumbing, electricity, and cisterns installed, respectively. It is concluded that there is a need for the inclusion of best management practices from the herd, livestock management, technical assistance and bookkeeping reorganising.

KEYWORDS: cattle, Caatinga, bookkeeping, Northeast, herd. 


\section{INTRODUÇÃO}

A criação de bovinos leiteiros desenvolvida no Semiárido do Nordeste do Brasil, na sua grande maioria, é composta por estabelecimentos familiares, com baixo nível de inovação tecnológica e sazonalidade da produção, em função dos períodos chuvoso e seco do ano. Os regimes de criação predominantes são o extensivo e o semi-intensivo, nos quais os animais utilizam a vegetação nativa do bioma Caatinga para sua mantença e produção.

No sistema extensivo é baixo o investimento em instalações, tendo o suporte alimentar baseado em pastos nativos e a suplementação concentrada e mineral, quando existente, nem sempre é adequada às exigências nutricionais do rebanho. Outro aspecto relevante é o baixo controle reprodutivo e sanitário, que conduz à baixa produtividade de leite por animal.

No sistema semi-intensivo, o criador detém maior controle sobre os animais, normalmente, passando parte do dia estabulados, fornecendo-lhes suplementação alimentar volumosa e concentrada, comumente utilizada no período seco ou durante todo o ano. Com isso, existe um maior interesse na melhoria do suporte forrageiro através da implantação de áreas para produção de volumosos sob irrigação e enriquecimento dos pastos nativos com culturas produtivas e resistentes à estiagem. Além disso, o controle sobre os aspectos sanitário e reprodutivo é favorecido, conduzindo a melhores índices produtivos em relação ao sistema extensivo.

Áreas de baixios (aluvião) e açudes são utilizadas para produção de alimentos volumosos para uso na suplementação da dieta. Nos períodos de secas prolongadas, os recursos naturais são tão exauridos que, em determinadas situações os animais não têm acesso à água para suprir suas necessidades hídricas. Em certas localidades de difícil acesso, os próprios moradores passam dificuldades para sobreviver.

Um forte entrave relacionado aos sistemas de produção de leite na região está relacionado com o baixo nível de capacidade gerencial dos produtores. Na maioria dos estabelecimentos não são contabilizados custos e/ou receitas, bem como a escrituração zootécnica da atividade. Diante desta realidade, é quase que impossível à realização de planejamento para investimentos no setor, sem o conhecimento de uma certeza futura.

A utilização dos recursos naturais da região já vem apresentando sinais de desgaste e esgotamento. $O$ corte da vegetação nativa para a venda de lenha visando à obtenção alternativa de renda está afetando drasticamente a cobertura vegetal sobre o solo, aliado a falta de práticas conservacionistas do seu uso, ofertando condições para a aceleração do processo erosivo sobre o solo.

A contaminação das fontes de água (açudes, barragens, poços, rios, etc.) com lixo, efluentes líquidos e sólidos (humano e animal), agrotóxicos e adubos químicos está se tornando cada vez mais comum tanto no meio rural quanto urbano, sendo necessário o estímulo de práticas para o uso e conservação deste recurso fundamental e valioso.

A taxa de lotação animal nos pastos nativos acima da recomendação contribui, ainda mais, no processo de esgotamento dos recursos forrageiros, afetando diretamente a rentabilidade produtiva do sistema. A otimização do uso dos recursos para o alcance de níveis 
satisfatórios de produção precisam ser fundamentados, evitando-se a maximização do uso e esgotamento dos recursos naturais disponíveis ao setor produtivo.

Analisando-se as condições sociais e econômicas dos envolvidos com o setor produtivo da bovinocultura de leite, é necessária uma análise e reflexão sobre que realidade estas pessoas vivem, principalmente, em relação aos fatores sociais, trabalhistas, saúde e educação.

O desenvolvimento de pesquisas voltadas ao conhecimento da estrutura e da distribuição espacial da pecuária leiteira no Brasil é de grande relevância para definição de políticas de infraestrutura, transporte, logística, análise de viabilidade de projetos de desenvolvimento regional e de programas de colonização e assentamento. É também importante para o estabelecimento de estratégias em vigilância sanitária, rastreabilidade, avaliação de risco geográfico de doenças e estudos de dinâmica do setor agropecuário (ZOCCAL, et al. 2006).

O estudo da caracterização do perfil dos sistemas de produção de leite bovino na Região Seridó do RN passa pela investigação das inter-relações entre os elementos discutidos acima. Diante disso, este estudo objetivou caracterizar os sistemas de criação de leite bovino instalados na região Semiárida Potiguar, baseado nos aspectos sociais, econômicos e zootécnicos visando contribuir na manutenção e aprimoramento da atividade leiteira na região.

\section{MATERIAL E MÉTODOS}

\subsection{Caracterização da área de estudo}

O trabalho foi realizado no município de Acari, mesorregião Central Potiguar e microrregião Seridó Oriental do Estado do Rio Grande do Norte. Conforme dados do Censo Demográfico - 2010, publicado pelo Instituto Brasileiro de Geografia e Estatísticas - IBGE, o município possui uma área territorial de $608,57 \mathrm{~km}^{2}$, com densidade demográfica de 18,13 habitantes $/ \mathrm{km}^{2}$ e população total de 11.035 habitantes, sendo que apenas $19,3 \%$ dos indivíduos são residentes no meio rural, que corresponde a 2.129 habitantes.

A sede do município tem uma altitude média de $270 \mathrm{~m}$ e apresenta coordenadas $06^{\circ} 26^{\prime} 9,6^{\prime \prime}$ de latitude sul e $36^{\circ} 38^{\prime} 20,4^{\prime \prime}$ de longitude oeste, distando da capital cerca de $219 \mathrm{~km}$, sendo seu acesso, a partir de Natal, efetuado através das rodovias pavimentadas BR-226 e BR427 (Beltrão et al., 2005).

No último Censo Agropecuário (IBGE, 2006), o setor rural era composto por 363 estabelecimentos agropecuários, com área média de 143,1 hectares (ha), sob diferentes sistemas de uso e produção, sendo identificado que 63\% (229) dos estabelecimentos produziram leite. 0 efetivo de rebanho bovino correspondia a 15.247 cabeças, sendo ordenhadas 3.802 vacas com produção de 4.182 .000 litros/leite/ano.

\subsection{Amostragem}

A amostra contemplou 28 propriedades rurais que desempenhavam a atividade da bovinocultura leiteira. Para a seleção das propriedades tomou-se por base um cadastro existente no Escritório Local do Instituto de Assistência Técnica e Extensão Rural do Rio Grande do Norte EMATER/RN, em que as propriedades foram selecionadas aleatoriamente buscando-se abranger às quatro regiões do município (norte, sul, leste e oeste). 


\subsection{Coleta dos dados}

A pesquisa foi realizada nos meses de setembro e outubro de 2011 com aplicação de questionários estruturados e entrevista direta aos produtores. A elaboração dos questionários buscou levar em consideração questões quantitativas e qualitativas que abordassem as dimensões zootécnica, econômica e social, vislumbrando alcançar um resultado instantâneo da realidade dos fatores envolvidos na atividade produtiva. Na dimensão zootécnica foram abordadas as seguintes questões: número total de animais do rebanho bovino, número total de vacas no rebanho, número de vacas produzindo leite, produção diária de leite, número de ordenhas diárias, padrão genético do rebanho, formas de suplementação alimentar, produção de silagem e/ou feno, assistência técnica obtida, práticas de manejo sanitário e disponibilidade de energia elétrica para produção. Na dimensão social foram aplicados os seguintes questionamentos: participação em cursos voltados para a atividade, escolaridade do entrevistado, idade do entrevistado, proximidade de unidade escolar na comunidade, tempo que desenvolve a atividade, disponibilidade de água encanada na moradia, unidade de atendimento à saúde na comunidade, associativismo, disponibilidade de cisterna para água de consumo humano e realização de tratamento na água de consumo humano. Na dimensão econômica foram indagadas as seguintes questões: área total da propriedade, condição no uso da terra, obtenção de renda em outras atividades, destinação do leite produzido, preço de comercialização do leite.

O questionário foi aplicado por um único entrevistador, buscando-se minimizar os efeitos da aplicação sobre a resposta do entrevistado, tendo a mesma sequência dos questionamentos em todas as entrevistas.

\subsection{Análise dos dados}

Os dados obtidos nas entrevistas foram organizados em planilha eletrônica do Microsoft Office Excel $2010^{\circledR}$, tendo sido obtidas variáveis dos tipos qualitativas e quantitativas, cabendo sempre que necessárias transformações para análise utilizando-se a estatística descritiva: média aritmética, desvio-padrão, mediana, porcentagem e valores mínimo e máximo.

\section{RESULTADOS E DISCUSSÃO}

\subsection{Características das propriedades}

Os resultados obtidos relacionados ao aspecto de condições de uso da terra estão descritos na Tabela 01. Observa-se que da amostra trabalhada 53,57\% (15) das unidades produtivas eram exploradas pelo seu proprietário. Uma questão relevante a ser discutida é a forma de acesso à propriedade, sendo em 53,33\% (08) obtidas através de herança, fator que pode caracterizar a continuidade das gerações no desenvolvimento da atividade. Em estudo desenvolvido por Sant'ana \& Costa (2004) em três municípios da mesorregião de São José do Rio Preto-SP, constataram que quase $60 \%$ dos chefes de famílias trabalhavam na propriedade rural dos pais e sua quase totalidade recebeu alguma herança na forma de terra dos pais ou, em frequência bem menor, do sogro (a). Em vários depoimentos constata-se que eles também contribuíram na aquisição ou ampliação desse patrimônio, quando trabalhavam com os pais. 
Tabela 01: Condições de uso da terra.

\begin{tabular}{llc}
\hline \multicolumn{1}{c}{ Proprietário } & $\mathbf{1 5}$ & $\mathbf{5 3 , 5 7 \%}$ \\
\hline Herança & 08 & $53,33 \%$ \\
Compra & 05 & $33,33 \%$ \\
Assentamento & 02 & $13,33 \%$ \\
\hline \multicolumn{1}{c}{ Outras formas de uso } & $\mathbf{1 3}$ & $\mathbf{4 6 , 4 3 \%}$ \\
\hline Morador & 06 & $46,15 \%$ \\
Parceiro & 03 & $23,08 \%$ \\
Cedida & 03 & $23,08 \%$ \\
Arrendamento & 01 & $7,69 \%$ \\
\hline
\end{tabular}

Ainda neste aspecto, outro fator deve ser analisado quando observadas as outras formas de uso da terra, em que "o morador", representa 46,15\% (06) dos entrevistados. Este formato de uso da terra caracteriza-se, geralmente, quando o proprietário da terra não reside no estabelecimento e tem sua renda principal advinda de outra atividade. Para que a propriedade não fique improdutiva ela é disponibiliza ao morador que passa a residir na propriedade e retirar o seu sustento e de sua família das atividades lá desenvolvidas ou recebe algum pagamento pelos serviços prestados. Em contrapartida, o proprietário passa a ser recompensado pelo morador com algum benefício da produção, como por exemplo, o manejo do seu rebanho, além da manutenção do seu patrimônio, a terra.

Na Tabela 02 verifica-se a distribuição das unidades de produção de leite quanto ao aspecto da sua área total. Quando questionados quanto ao tamanho da área da propriedade alguns entrevistados não tiveram conhecimento para informá-la, correspondendo a $25 \%$ (07) da amostra, outros tinham a informação apenas das medidas em "braças", unidade de medida linear que equivale a 2,20 metros. O conhecimento da área e características da propriedade rural é indispensável ao seu planejamento, sendo norteador na determinação do tipo de exploração e na capacidade de suporte para o rebanho, principalmente, quando se tem como suporte forrageiro a vegetação nativa.

Outro aspecto que deve ser observado é a preservação obrigatória da reserva legal, sendo para o bioma Caatinga correspondente a, pelo ao menos, $20 \%$ da área total da propriedade. Nas entrevistas, apenas em um sistema de produção foi informado que havia a delimitação respeitada, o que nos conduz a repensar os meios de conscientização e atuação prática para melhorias destes sistemas neste quesito.

As propriedades com área conhecida representaram 75\% (21) da amostra, sendo 32,15\% (9) com área até 100 ha e 42,86\% (12) acima de 100 ha. As dimensões dos empreendimentos foram 12 e 1200 ha para o menor e maior, respectivamente, e mediana da área das propriedades com área conhecida equivalente a 135 hectares.

Tabela 02: Área total das propriedades

\begin{tabular}{lcc} 
Tamanho da propriedade (hectares) & FREQ. & $\%$ \\
\hline Até 50 & 05 & 17,86 \\
De 51 a 100 & 04 & 14,29 \\
De 101 a 200 & 06 & 21,43 \\
Acima de 200 & 06 & 21,43
\end{tabular}




\begin{tabular}{lll} 
Não informada & 07 & 25,00 \\
\hline Total & $\mathbf{2 8}$ & $\mathbf{1 0 0 , 0 0}$ \\
\hline
\end{tabular}

\subsection{Características do rebanho e do manejo adotado}

Os rebanhos identificados durante a pesquisa correspondem a animais mestiços sem padrão racial definido (SRD) proporcionado pelos sucessivos acasalamentos ao longo do tempo entre diferentes raças. O número de bovinos no rebanho variou de 11 até 350 cabeças para o menor e maior rebanho, respectivamente, e mediana de 51 cabeças. A Tabela 03 destaca as informações de tamanho do rebanho bovino, número de vacas do rebanho e número de vacas em lactação. Partindo da informação do número total de animais do rebanho foi identificado que a soma das classes 01 e 02 com representatividade até 60 cabeças, representa 67,85\% (19) dos rebanhos da amostra e a classe 05 equivale a 14,29\% (4) dos rebanhos acima de 120 cabeças. A identificação do rebanho total da propriedade é um dado fundamental, pois com ele é possível executar o planejamento geral da propriedade em todos os aspectos, sendo mais especificamente relacionado com o manejo sanitário, alimentar, reprodutivo, área, infraestrutura, mão-de-obra e insumos em geral para a produção.

O número de vacas do rebanho pode representar potencial reprodutivo e produtivo para o estabelecimento que desenvolve a produção de leite, tendo nela o principal componente na composição da renda obtida, além da possibilidade de venda e troca de animais. Para esta condição, os valores mínimo e máximo foram 04 e 73 cabeças de vacas no rebanho, respectivamente. Damos destaque às classes 06 e 07, que juntas representam $71,43 \%$ (19) das propriedades estudadas que compreendem o número de até 27 vacas no rebanho.

Para o número de vacas em lactação obteve-se o valor mínimo de 02 e máximo 42 vacas em lactação. As classes 12 e 13 representam o percentual de 85,72\% (24) das propriedades em estudo, refletindo rebanhos com até 23 animais em lactação.

Tabela 03: Número total de animais do rebanho bovino, número de vacas do rebanho e número de vacas em lactação.

\begin{tabular}{lccc}
\hline \multicolumn{4}{c}{ Número total de animais do rebanho bovino } \\
\hline CLASSES & CABEÇAS & FREQ. & $\%$ \\
$\mathbf{0 1}$ & 11 a 30 & 10 & 35,71 \\
$\mathbf{0 2}$ & 31 a 60 & 09 & 32,14 \\
$\mathbf{0 3}$ & 61 a 90 & 04 & 14,29 \\
$\mathbf{0 4}$ & 91 a 120 & 01 & 3,57 \\
$\mathbf{0 5}$ & Acima de 120 & 04 & 14,29 \\
\hline Total & \multicolumn{4}{c}{ Número total de vacas do rebanho } \\
\hline \multicolumn{5}{c}{ CLASSES } & FREQ. & $\mathbf{1 0 0}$ \\
$\mathbf{0 6}$ & CABEÇAS & 13 & 46,43 \\
$\mathbf{0 7}$ & 4 a 15 & 07 & 25,00 \\
$\mathbf{0 8}$ & 16 a 27 & 04 & 14,29 \\
$\mathbf{0 9}$ & 28 a 39 & 02 & 7,14 \\
$\mathbf{1 0}$ & 40 a 51 & 01 & 3,57 \\
$\mathbf{1 1}$ & 52 a 63 & 01 & 3,57 \\
\hline
\end{tabular}




\begin{tabular}{lccc}
\hline Total & \multicolumn{2}{c}{$\mathbf{2 8}$} & $\mathbf{1 0 0 , 0 0}$ \\
\hline \multicolumn{1}{c}{ Número de vacas em lactação } & \\
$\mathbf{1 2}$ & CABEÇAS & FREQ. & $\mathbf{\%}$ \\
13 & 2 a 12 & 18 & 64,29 \\
14 & 13 a 23 & 06 & 21,43 \\
15 & 24 a 34 & 02 & 7,14 \\
\hline Total & 35 a 45 & 02 & 7,14 \\
\hline
\end{tabular}

A ordenha manual com bezerro ao pé foi identificada em todas as propriedades do estudo. Em 22 (78,57\%) propriedades a ordenha era realizada uma única vez ao dia, enquanto nas $06(21,43 \%)$ propriedades restantes eram feitas duas vezes ao dia. O manejo com apenas uma ordenha diária pode estar relacionado pelo interesse, por parte do criador, em obter a produção de leite para a manutenção do sistema produtivo, assim como a obtenção de crias com melhor desenvolvimento, podendo ser utilizadas na complementação da receita do estabelecimento. Já no manejo com duas ordenha diárias o produtor visualiza claramente o interesse à produção de leite, tendo as crias como um co-produto da atividade. Nesta realidade, cabe a cada produtor definir, de acordo com sua análise, qual o tipo de manejo a ser mantido na sua atividade produtiva.

Os dados de produção de leite dos rebanhos coletados na pesquisa estão apresentados na Tabela 04. Nela, destacou-se, principalmente, a informação da média de produção diária por vaca que foi de 3,91 L/vaca/dia, considerando-se uma lactação de 300 dias e o intervalo de partos de 01 ano, a produção média seria de 1173 litros/vaca/ano, resultado inferior ao publicado por Zoccal (2012), com resultados de 1340 litros/vaca/ano em 2010 e 1374 litros/vaca/ano estimados para 2011, referentes à produção média nacional. Estudos desenvolvidos por Zoccal (2008), relacionados à cadeia produtiva do leite no estado do Ceará apresentam resultados semelhantes, tendo nos rebanhos com produção de até 50 litros/dia a produtividade de 3,5 litros de leite por vaca em lactação por dia.

Tabela 04: Resultados zootécnicos dos rebanhos.

\begin{tabular}{lcc}
\hline Variáveis & Média & Desvio Padrão \\
\hline Número de vacas do rebanho - cabeça & 22,89 & 16,59 \\
Número de vacas em lactação - cabeça & 13,36 & 10,10 \\
Produção de leite diária - litro/dia & 52,21 & 44,21 \\
Preço do litro de leite vendido - R\$̧/litro & 0,81 & 0,05 \\
Média de produção por vaca - litro/dia & 3,91 & - \\
\hline
\end{tabular}

O percentual de vacas em lactação em relação ao número total de animais do rebanho, como também em relação ao número de vacas do rebanho são parâmetros para definir a eficiência reprodutiva e produtiva na produção de leite. De acordo com recomendações da Empresa Brasileira de Pesquisa Agropecuária - EMBRAPA, o número de vacas em lactação deve ser, no mínimo, $40 \%$ do número total de animais do rebanho e $75 \%$ do número total de vacas do estabelecimento. Neste estudo, o percentual médio de vacas em lactação representou $18,71 \%$ em relação ao número total de animais do rebanho e $58,37 \%$ em relação ao número total de vacas do rebanho, ambos abaixo da recomendação citada. Ainda segundo Faria (2007), o índice de vacas em lactação em relação ao número de animais do rebanho, quando bem conduzidos, 
deveria ser entre 50 e $55 \%$ e o percentual de vacas em lactação em relação ao total de vacas do rebanho de 80 a $85 \%$, índices que se distanciam mais ainda dos identificados na amostra.

Os resultados identificados na pesquisa demonstram que a composição do rebanho, especificamente, quanto ao número de vacas e seu percentual em lactação estão abaixo dos recomendados. A situação apresentada pode estar relacionada às dificuldades enfrentadas pelos criadores nos aspectos dos manejos alimentar, sanitário e reprodutivo o que acarreta desequilíbrios na evolução do rebanho.

O sistema de criação adotado em todas as propriedades avaliadas foi do tipo semiintensivo, tendo a vegetação nativa como suporte forrageiro, principalmente, no período chuvoso do ano, quando há maior disponibilidade de alimentos e, no período seco (estiagem), o principal volumoso utilizado é o capim elefante (Penissettum purpureum) fornecido no cocho. Ainda com relação ao manejo alimentar foi constatado que $60,71 \%$ (17) dos entrevistados já haviam participado de alguma atividade relativa à conservação de forragens na forma de feno e silagem. Porém, quando indagados sobre a prática destas técnicas como estratégia alimentar para sustentação do rebanho 92,86\% (26) informaram não executá-las na propriedade.

O destino da produção de leite está representado na Tabela 05. Nela observa-se um papel muito forte do agente intermediário da venda do leite (atravessador), que correspondeu a $67,86 \%$ (19) dos estabelecimentos e $70,93 \%$ do volume de leite produzido adquirido por este segmento do mercado. Segundo Durr \& Costa (2008) os atravessadores são definidos como todos os pequenos comerciantes no interior dos municípios que compram produtos dos agricultores e/ou que vendem para o consumidor local. O resultado deste formato de coleta apresenta resultados positivos, no caso do leite, quando este é destinado aos estabelecimentos com registro de inspeção sanitária, podendo garantir melhores condições de higiene no processamento do produto. Porém, isto só é possível quando o transporte é realizado dentro das condições ideais de higiene e temperatura.

Tabela 05: Destino do leite produzido.

\begin{tabular}{lccc}
\hline Destino da produção de leite & Freq & \% & \% do leite produzido \\
\hline Queijeira & 04 & 14,29 & 19,50 \\
Laticínio & 02 & 7,14 & 7,93 \\
Atravessador & 19 & 67,86 & 70,93 \\
Consumo próprio & 03 & 10,71 & 1,64 \\
\hline Total & $\mathbf{2 8}$ & $\mathbf{1 0 0 , 0 0}$ & $\mathbf{1 0 0 , 0 0}$ \\
\hline
\end{tabular}

Entendemos como negativo o decréscimo no valor pago por litro de leite ao criador, que teve preço médio de venda equivalente a $R \$ 0,81 \pm 0,05$, para dedução dos custos do transporte no valor pago. Dependendo do volume de leite coletado, o intermediário (atravessador) pode até alcançar melhor rentabilidade na sua atividade do que o criador. A coleta de leite em maior escala para abastecimento de "queijeiras" que não possuam os padrões mínimos de higiene também pode ser considerado um fator impactante para este segmento da cadeia. Ainda com relação ao destino da produção de leite foi observado que 10,71\% (03) produtores tinham a produção de leite voltada para o consumo pela família, que equivale a apenas $1,64 \%$ do volume de leite produzido. 
A assistência técnica rural é indefinidamente um componente de extrema importância para o desenvolvimento da atividade agropecuária em geral, sendo caracterizado como um agente de transformação da realidade do campo. Neste estudo, como observado no Gráfico 01, os resultados quanto ao acesso direto à assistência técnica foi desanimador, tendo 64,29\% (18) dos entrevistados informado não receber qualquer acompanhamento técnico, seja ele particular ou público. Resultado semelhante foi apresentado pelo Sebrae/GO (2010), em estudo desenvolvido junto à 540 propriedades rurais nas regiões Oeste e Noroeste de Goiás identificou que $70 \%$ das propriedades não tem acesso à consultoria e assistência técnica. Lima et al. (2011), em avaliação a um projeto de assistência técnica em Quixeramobim/CE, constataram que a falta de recursos financeiros, técnicos despreparados e descontinuidade na assistência técnica foram fatores que tiveram efeitos negativos sobre os resultados produtivos e na acreditação da assistência por parte dos produtores.

Sendo o Brasil um país eminentemente agrícola e desejando despontar dentre os maiores produtores mundiais no agronegócio, torna-se necessário o investimento na disponibilização de assistência técnica em quantidade e qualidade adequadas para atender a este público, que se encontra esquecido na sua simples realidade produtiva, sem aplicação das novas ferramentas tecnológicas disponíveis que possam proporcionar-lhes melhores respostas produtivas e econômicas.

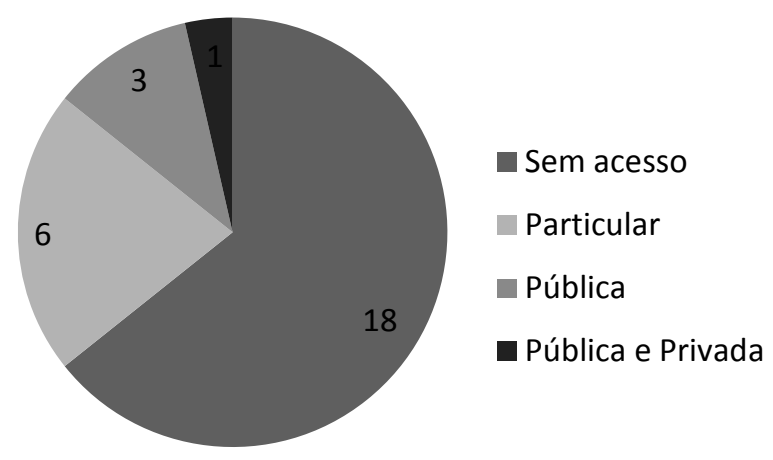

Gráfico 01: Situação de acesso à assistência técnica rural.

Os resultados alcançados junto aos produtores com relação à escrituração zootécnica do rebanho demonstraram que apenas $46,43 \%$ (13) realizam anotações, mesmo assim com deficiências, dando ênfase principalmente às vacinações preventivas contra febre aftosa e raiva, impulsionadas, principalmente, pela obrigatoriedade na sua execução. Conforme destaca Lima et al. (2011), as propriedades rurais no Nordeste do Brasil, independente de tamanho ou nível de conhecimento do proprietário, geralmente apresentam dificuldades na implementação das recomendações técnicas para o setor, dificultando a obtenção de resultados zootécnicos e econômicos mais satisfatórios nestes estabelecimentos.

\subsection{Características sociais}

Partindo para a análise das características relacionadas ao fator humano envolvido na atividade produtiva do leite, apresenta-se no Gráfico 02 a distribuição referente ao nível de 
escolaridade dos entrevistados na pesquisa. Observou-se o predomínio de entrevistados com ensino fundamental incompleto, correspondente a $78,57 \%$ da amostra.

Associando-se o fator escolaridade à idade dos entrevistados, que apresentou média de $51 \pm 10,85$ anos de idade, podemos tecer à conclusão de que o acesso e permanência em relação à educação pelo homem do campo no período anterior aos anos 70 eram precários. Resultados semelhantes foram obtidos por Gomes (2011) estudando sistemas de produção de leite bovino no Cariri paraibano, em que $84 \%$ dos representantes da amostra possuíam apenas ensino fundamental e/ou médio.

Analisando os resultados do Censo Demográfico 2010, foi destacado por Brasil (2011) que em 2010, 9,6\% da população brasileira com 15 anos ou mais não era alfabetizada. A taxa de analfabetismo era maior nas faixas de idade mais elevadas - a população com 60 anos ou mais concentrava o maior percentual de analfabetos (26,5\%), seguida pela faixa etária entre 50 e 59 anos (13,8\%). Nas faixas mais jovens, este percentual caiu para 2,2\% entre 15 e 19 anos e para $3,4 \%$ para a população entre 20 a 29 anos. Isso demonstra que a dificuldade de acesso à escola antes encontrada, de alguma forma vem diminuindo nos últimos anos.

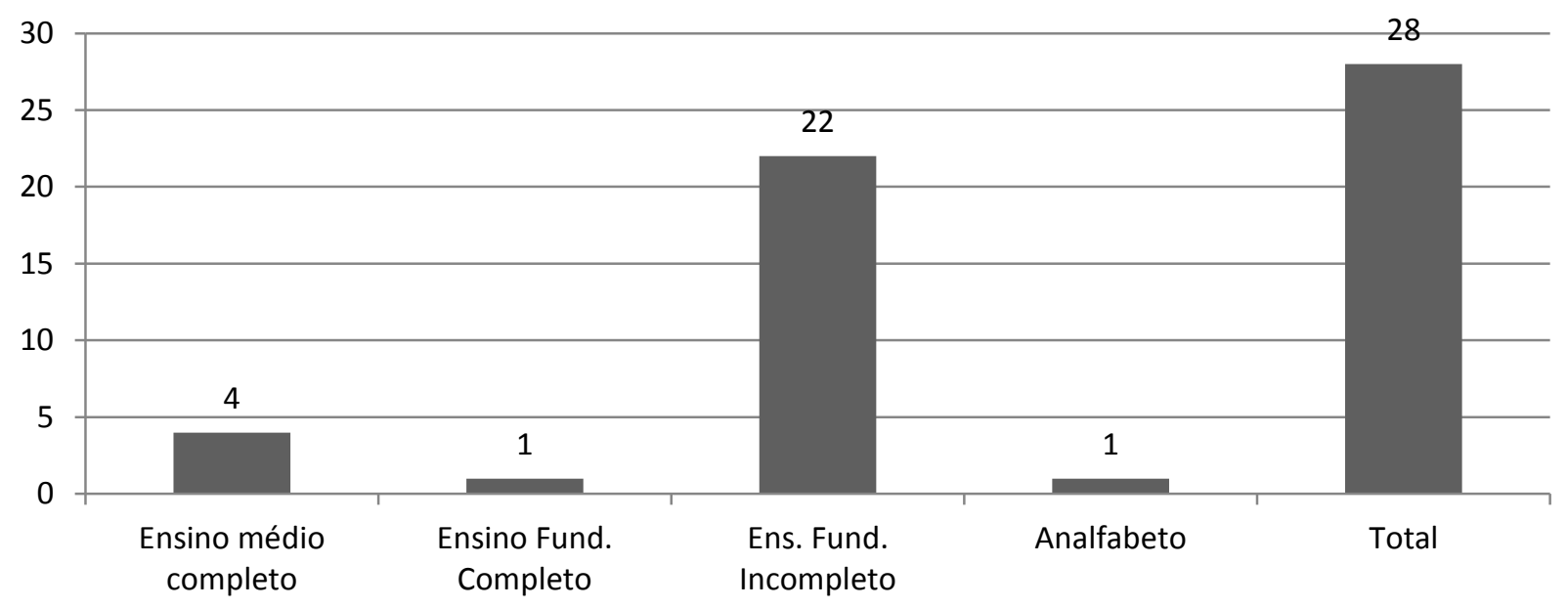

Gráfico 02: Distribuição dos entrevistados quanto ao nível de escolaridade.

A infraestrutura que possa contribuir para o bem estar social e qualidade de vida no meio rural obtidos no estudo demonstrou resultados bastante positivos, tendo 96,43\% (27), 100\% (28) e $85,71 \%$ (24) dos estabelecimentos, respectivamente, com água encanada, energia elétrica e cisternas instaladas. Os fatores que contribuíram significativamente para a melhoria destes índices foi o desenvolvimento de programas governamentais para melhoria das condições de moradia e redução da pobreza rural, como o Programa de Desenvolvimento Solidário (PDS), Luz para Todos e Um Milhão de Cisternas (P1MC). De acordo com informativo do Ministério de Minas e Energia - MME (2012), de 2003 até janeiro de 2012 já foram beneficiadas 2,9 milhões de famílias no meio rural com acesso à energia elétrica, sendo 1,4 milhão na região Nordeste. 


\section{CONCLUSÃO}

A atividade produtiva do leite bovino na região estudada apresenta deficiências na sua organização fundiária e nos aspectos zootécnicos e sociais. Diante disso, vislumbrando-se o alcance de resultados mais satisfatórios, torna-se necessária à inclusão de melhores práticas de manejo do rebanho, sobretudo, no aspecto alimentar, melhoramento genético do rebanho, escrituração zootécnica e assistência técnica visando o desenvolvimento profissional dos envolvidos no setor e alcance de melhores índices produtivos.

No aspecto social é conveniente desenvolver um trabalho de reorganização fundiária, de forma que facilite aos usuários da terra à sua posse. Além disso, contribuir para a melhoria da qualidade de vida rural, de forma que as famílias permaneçam no campo com segurança, retirando o seu sustento da terra, na tentativa de minimizar cada vez mais o êxodo, em direção aos centros urbanos, daqueles que desenvolvem alguma atividade no setor rural.

Os resultados apresentados nesta pesquisa não sofreram grandes transformações nos últimos anos, sendo estas informações importantes e necessárias para o planejamento de ações voltadas para o melhor desempenho da atividade pecuária na região e melhor ocupação da terra, bem como ser uma base norteadora para futuros estudos.

\section{REFERÊNCIAS BIBILIOGRÁFICAS}

1. BRASIL. Presidência da República. Secretaria de Comunicação Social. Destaques: Secretaria de Comunicação, ano 4, no 1, jan./jul. 2011. Brasília: SECOM, 2011. v.: il. - Quadrimestral.

2. BELTRÃO, B. A. et al. Projeto cadastro de fontes de abastecimento por água subterrânea Estado do Rio Grande do Norte: diagnóstico do município de Acari. Ministério de Minas e Energia. Recife, 2005.

3. DURR, J.; COSTA, F.A. Cadeias produtivas de base agrária e desenvolvimento regional: o caso da região do Baixo Tocantins. Amazônia: Ciência \& Desenvolvimento, Belém, v.3, n.6, jan./jun., 2008.

4. EMBRAPA - Empresa Brasileira de Pesquisa Agropecuária: Gado de Leite. Estatísticas do leite: recomendações para o bom desempenho da atividade leiteira. 2012. Disponível em: <http://www.cnpgl.embrapa.br/nova/informacoes/estatisticas/insumo/tabela0131.php>. Acesso em: 20 out. 2013.

5. FARIA, V.P. 2007. Fatores que afetam a eficiência. DBO Mundo do Leite 27:2-15.

6. GOMES, J.T. Aspectos socioeconômicos e ambientais da atividade leiteira no Cariri paraibano. 2011. 126f. Tese (Doutorado em Zootecnia) - Programa de Doutorado Integrado em Zootecnia, Universidade Federal da Paraíba, Areia. 2011.

7. IBGE - Instituto Brasileiro de Geografia e Estatísticas. Censo Agropecuário 2006. Disponível em: <http://www.ibge.gov.br/home/estatistica/economia/agropecuaria/censoagro/2006/ defalt.shtm>. Acesso em: 03 out. 2013.

8. __ Censo Demográfico 2010. Disponível em: <http://www.censo2010.ibge.gov.br/>. Acesso em: 25 set. 2013.

9. LIMA, P.O. et al. Avaliação de propriedades rurais após implantação de programa de 
assistência técnica. Revista Acta Veterinaria Brasilica, Mossoró, v.5, n.2, p. 192-196, 2011.

10. MME - Ministério de Minas e Energia. Informativo Luz para Todos, n.38, fev., 2012. Disponível em: <http://luzparatodos.mme.gov.br/luzparatodos/Asp/informativos.asp>. Acesso em: 12 ago. 2013.

11. SANT'ANA, A.L.; COSTA, V.M.H.M. Produtores familiares e estratégias ligadas à terra. Revista de Economia e Sociologia Rural, Rio de Janeiro, vol. 42, n.04, p. 663-683, out./dez., 2004.

12. SEBRAE/GO - Serviço de Apoio às Pequenas e Médias Empresas de Goiás. Relatório de pesquisa do projeto arranjo produtivo lácteo: bacia leiteira oeste goiano. Goiânia: SEBRAE, 2010.

13. ZOCCAL, R.; ASSIS, A. G.; EVANGELISTA, S.R.M. Distribuição geográfica da pecuária leiteira no Brasil. Juiz de Fora: Embrapa, 2006. (Circular Técnica, 88).

14. ZOCCAL, R. et al. Competitividade da cadeia produtiva do leite no Ceará: produção primária. Juiz de Fora: Embrapa Gado de Leite, 2008. 384p.

15. ZOCCAL, R. Efetivo bovino, vacas ordenhadas e produção de leite no Brasil, 1975 a 2010. 2012. <http://www.cnpgl.embrapa.br/nova/informacoes/estatisticas/producao/ tabela0232.php>. Acesso em: 10 out. 2013. 